\title{
Beginning an African Stock Markets Integration? A Wavelet Analysis
}

\author{
Grakolet Arnold Zamereith GOURENE ${ }^{1+}$, Pierre MENDY², Lanciné DIOMANDE1 \\ ${ }^{1}$ Jean Lorougnon Guédé University, Côte d'Ivoire, \\ ${ }^{2}$ Cheikh Anta Diop University, Sénégal
}

\begin{abstract}
This is a study on the integration between the six largest African stock markets at different timescales. The study determines whether the various measures and reforms undertaken to integrate the African stock markets have been effective. Wavelet methods and the Diebold and Yilmaz (2012) spillovers index were used. This approach allows an analysis in both time and frequency. The study results reveal that the integration of African stock exchanges is low at smaller time scales but tends to grow at larger timescales. Despite all the reforms, the transmission of financial information from one market to other remains slow. However, large-scale integration appears to decline in recent years. More effective policies are therefore needed for faster transmission and more efficient integration of African financial markets as well as for promoting exchanges between African stock markets.
\end{abstract}

Keywords: African Stock Markets Integration, Wavelet Multiple Correlation, Generalized VAR, Time scales JEL Classifications: $F 3, C l, G 1$

Received 20 December2018, Revised 6 May 2019, Accepted 10 May 2019

\section{Introduction}

The past decades have witnessed a growth phase in the African stock markets. Several stock markets in various countries have been established and the performance of a few have been noteworthy (PwC 2015, 2016, ASEA 2012, 2015). The number of stock markets has nearly doubled (from 12 to 25) in recent times. Capitalization of the 10 largest African stock markets has recorded exceptional growth of $390.77 \%$ from 2000 to 2010. Between 2007 and 2009,

+Corresponding Author: Grakolet Arnold Zamereith GOURENE

Assistant Professor, Laboratory of Research in Economics and Management, Jean Lorougnon Guédé University, P.O. Box V 25 Daloa, Cote d'Ivoire, Tel: +22508416062, E-mail: grakolet88@gmail.com

Co-Author: Pierre MENDY

Full Professor, Laboratory of Mathematics of Decision and Numerical Analysis, Cheikh Anta Diop University, P.O. Box 5005 Dakar-Fann, Sénégal, E-mail: mendy4163@gmail.com

Co-Author: Lanciné DIOMANDE

Assistant Professor, Laboratory of Research in Economics and Management, Jean Lorougnon Guédé University, P.O. Box V 25 Daloa, Cote d'Ivoire, E-mail: diomandelancine2010@yahoo

Acknowledgements: We would like to thank the Editor-in-Chief of the Journal of Economic Integration (JEI) and the anonymous reviewer for the constructive comments and remarks, which helped us to greatly improve the manuscript. The content, views and the recommendations in this paper are those of the authors and do not necessarily reflect the views of the different African exchanges and their boards of director. Errors remain our responsibility. 
nearly 200 new companies have posted more than 10 billion US dollars 1 ) of capital on 18 African stock exchanges as part of their IPO2) offering. Between 2011 and 2016, approximately 6.1 billion US dollars was raised through 125 IPOs. Rapid development of financial markets has a positive influence on African economies. Indeed, Bagehot (1873), Hicks (1969) and Schumpeter (1912) confirmed that capital and technical innovation were promoted by good financial institutions. Levine (1997) stated that financial market plays a prominent role in the growth, capital accumulation, and economic development. However, this rapid growth in financial markets does not appear to be sufficient yet, because, by 2015, African financial markets accounted for only $1.4 \%$ of the world's market capitalization. $\left.{ }^{3}\right)$ These results show that African financial markets, despite their notable advances, certainly lag in global finance.

Literature shows that a more integrated African financial market would be more efficient and therefore more internationally competitive. Fish and Biekpe (2002) contend that an African regional stock exchange may improve liquidity while reducing the cost of operations. Irving (2005) asserts that integrating African financial markets would allow a better depth and wider choice of financial products. According to ECA (2008), integration of financial market increases the liquidity in African financial markets. Lugangwa (2012) shows that the cooperation among and integration of African markets will increase their visibility among global investors. Considering their limited sizes, UNCTAD (2014) suggests that African financial markets should unite at a continental or regional scale for further development.

There have been several reforms and measures undertaken to integrate the African stock markets within and outside. The African Securities Exchanges Association (ASEA) ${ }^{4}$ was established to improve the global visibility of African Securities, provide better information on African stock market, and promote trade between African financial markets. Two regional stock exchanges, the Bourse Regionale des Valeurs Mobilieres (BRVM) from the WAEMU5) and the Bourse des Valeurs Mobilieres de l'Afrique Centrale (BVMAC) from the CEMAC6), were also established. The stock exchanges of WAEMU Nigeria and WAEMU Morocco collaborated with Paris EUROPLACE, the London Stock Exchange Group (LSEG), and the Financial Times Stock Exchange (FTSE) Group. Since 2011, ASEA, in partnership with the FTSE, created two indices: the FTSE ASEA pan African Index Series and the FTSE ASEA pan Africa Index ex South Africa. The indices highlight the performance of African stock markets (ASEA 2015). In 2013, the Economic Community of West African States (ECOWAS) launched the West African Capital Markets Integration Council (WACMIC). WACMIC's

\footnotetext{
1) Billion

2) Initial Public Offering

3) With $77 \%$ coming only from the South African stock market

4) URL:http://www.african-exchanges.org/

5) West African Economic and Monetary Union

6) Central African Economic and Monetary Community
} 
objective is to establish a harmonized regulatory environment for trading of financial securities in the region. On April 1, 2015, Phase 1 of this project with a sponsored access trading was launched. The other phases focus on a common passport for qualified West African brokers in the ECOWAS and the establishment of a common trading platform in the region. In 2014, East African stock markets including Kenya took steps toward a harmonized capital market (UNCTAD 2014, PwC 2015). These measures encouraged the cross-listing initiative that allows companies to cross over from one stock market to another. Moreover, there is also a road map for the integration of the East African Community (EAC) capital markets. Several measures are underway to integrate stock exchanges within the Arab Maghreb Union (AMU). Cooperation and agreements have been signed between members to enable investors to intervene in all stock markets of the region (ARIA III 2008). In Southern African Development Community (SADC), the Committee of SADC Stock Exchanges (COSSE) was established in 1997. Some of its goals include the development of a harmonized securities market in the region and the cooperation among the member stock exchanges.

Several authors are interested in the integration of African financial markets. In particular, Collins and Biekpe (2003a,b) and Wang et al. (2003) were interested in the integration of African stock markets during and after the 1997 Asian crisis. Adjasi and Biekpe (2006), Agyei-Ampomah (2008), Boamah (2013), Boako and Alagidede (2016), and Mensah and Alagidede (2017) studied the interrelation between African stock exchanges. Using the Diebold and Yilmaz (2012) spillovers index, Sugimoto et al. (2014), Fowowe and Shuaibu (2016), and Boako and Alagidede (2018) analyzed the relationship between the African stock markets during and after the US financial crisis and the European debt crisis. There is a consensus among researchers that African financial markets were decoupled even in times of crisis. In contrast to earlier studies, which consider only the temporal dimension of the relations between the stock markets, the present study favors a concurrent analysis in time and frequency. This approach is based on the wavelet method (Percival and Walden 2000), which is relevant because these methods allow the analysis of the dynamic relationship between financial markets by considering their co-movement over several timescales. In fact, stock markets are a complex system composed of different agents with different trading horizons that form the markets dynamics. Heterogeneous investors make decisions based on their investment horizon (scale) (Candelon et al. 2005). Therefore, it appears unrealistic to not consider these different horizons or scales in the analysis of the co-movement between stock markets. The time and frequency analysis appears, therefore, best suited for the study of relations between stock markets. First, the Wavelet multiple and the Wavelet multiple cross correlation proposed by Fernandez-Macho (2012) are used to analyze the co-movement between African stock markets at different timescales. Then, the stock market data is transformed using the Maximal Overlap Discrete Wavelet Transform (MODWT) to obtain the data at different timescales. Finally, the Diebold and Yilmaz 
(2012) spillovers index is constructed from the transformed data to determine the spillovers between African stock markets according to the timescales. The study by Boako and Alagidede (2017) is believed to be the only work related to the integration between African markets using wavelets correlation. However, unlike the present study, these studies focused on the transmission of volatility between African financial markets rather than on returns.

The present study aims to determine, given the complex characteristics (horizons and timescales) of stock markets, whether the several measures and reforms undertaken to integrate the African stock markets have been effective. In the time and frequency analysis framework, the degree of integration between financial markets is measured based on the speed at which financial information is transmitted between the markets. In fact, the more the stock markets are integrated, the faster is the transmission of information among the markets, and is therefore present at high frequencies (Fernandez-Macho 2012, Tiwari et al. 2013). The present study contributes to literature in three ways. First, it mitigates the limitations of previous studies by focusing on the dynamic evolution of relations between African financial markets over several timescales. Second, both integration and spillovers between African stock markets are analyzed. Here the spillovers are taken as consequences of stock markets integration (Hooy and Lim 2013). In addition, interestingly, the analysis period covers not only the last two financial crises (the US financial crisis and the European debt crisis) but also the recent development of African stock markets. In fact, despite the resilience of the African financial markets, the financial crises have led to a slight integration in emerging stock markets (Lehkonen 2014). Although the financial crises have no direct impact on African financial markets, they may have indirect effects on the value and capital outflows, and on the margin applied to loans on international financial markets, especially for emerging and African countries. This can compel the players in these markets to borrow locally (Kasekende et al. 2009).

Section 2 of this study gives an overview of the literature on stock markets integration. Section 3 details the econometric methodology used. Section 4 examines the data and the empirical results and Section 5 concludes.

\section{Literature Review}

Integration of African stock markets has attracted academic interests. Collins and Biekpe (2003a) showed that the most developed African stock markets, namely Egypt and South Africa, suffered from contagion during the 1997 Hong Kong crisis. Collins and Biekpe (2003b) contended that there is a decline in the co-movement of African financial markets in regional blocs. Using co-integration and error correction model, Wang et al. (2003) revealed that integration between African stock markets has varied over time and appears to have declined 
after the 1997 Asian crisis. Adjasi and Biekpe (2006) found a unique long-term relationship between African stock markets and a short-term dynamic of African stock markets returns that affect the South African and Ghanaian stock exchanges. Adopting the Barari (2004) method of measuring the score market integration, Agyei-Ampomah (2008) found a low level of correlation between the African stock markets. Recently, Boamah (2013) showed through a multifactor pricing model that the integration of the African stock markets evolved over time. Using the Diebold and Yilmaz (2012) spillovers index, Sugimoto et al. (2014) and Fowowe and Shuaibu (2016) concluded that there are weak spillovers between African financial markets.

Boako and Alagidede (2017) revealed that African financial markets exhibit a partial deterministic convergence both globally and regionally and have not yet reached the integration levels of their global counterparts. Using copulas, Mensah and Alagidede (2017) analyzed the dependence structure of the emerging African stock markets and advanced stock markets. They found that the dependence was low for almost all African stock markets except for South Africa and varied over time. They also found the presence of an asymmetric dependence, irrespective of a bearish or bullish market. Finally, they found that the emerging stock markets in Africa remained unaffected by the extreme decline in stock prices on developed markets. Boako and Alagidede (2018) used the asset pricing model to examine whether African stock markets were decoupled or recoupled during the US financial crisis. The asset pricing model considers the effects of volatility before, during, and after the US financial crisis and the recoupling (decoupling) of the model as spreading (no spreading) shocks. They showed that the correlation between African stock markets and global stock markets increased and the shocks came mainly from North Africa, Southern Africa, West Africa, and other emerging markets. They also found that African stock markets seem to decouple from world shocks rather than regional shocks.

With regarding the wavelet literature on the integration of financial markets, it is relatively recent, and hence there is a lack of studies focusing on Africa, except for the works of Boako and Alagidede (2017), which examined the regional and global integration of African stock market volatilities using wavelet methods. They analyzed the relationship between four African stock markets, global markets, the euro-dollar bilateral exchange rate, and regional markets in Africa. Their results showed the presence of strong short-term co-movements and revealed segmentation between certain African stock markets and the volatility of euro-dollar exchange rates. At the global level, the studies by Gallegati (2005) show that the MENA stock markets are neither regionally nor internationally integrated. Similarly, Rua et al. (2009) found that the Japanese stock market was poorly integrated with the other developed financial markets. ${ }^{7}$ ) The relationship between these stock markets varied with timescales. Graham and Nikkinen (2011) showed that the co-movement between Finland and the emerging stock markets was reduced to long-term fluctuations. In terms of the co-movement with the stock markets of the

7) Germany, U.K and U.S 
developed regions, ${ }^{8)}$ it was seen to be present in all frequencies with strong co-movements at high frequencies. Graham et al. (2012) found a strong co-movement between stock markets that differs from one country to another. They found that the US stock market is highly correlated to the stock markets of Brazil, Mexico, and Korea, but has a weak co-movement with the Egyptian and Moroccan stock markets. During the US financial crisis, there was a low level of movement between stock markets. Graham et al. (2013) found a low co-movement at small scales but strong at large scales between the MENA and US stock markets. On the other hand, Fernandez-Macho (2012) proposed two new wavelet methods: the Wavelet Multiple Correlation and the Wavelet Multiple Cross-Correlation. These methods were applied to the analysis of the co-movement of the European stock markets. The wavelet multiple correlation underlined a strong correlation between eurozone stock markets that is nearly perfect in the long run. They also showed small inconsistencies between the euro stock markets in the short and medium term, which must be the result of the interaction of different agents with different decision-making horizons on the stock markets. The wavelet multiple cross-correlation method showed that the CAC40 appears to statistically lead the rest of the euro's financial markets in the short and medium term, that is, from a week to a month. Madaleno and Pinho (2012) showed that the strength or weakness of co-movement between financial markets depended on timescales. Recently, using the methods proposed by Fernandez-Macho (2012), Tiwari et al. (2013) showed that Asian stock markets were strongly integrated at low frequencies but less integrated at high frequencies. Loh (2013) found a correlation between the Asia-Pacific stock markets and European and American stock markets and noted it had increased during the US financial crisis. Aloui and Hkiri (2014) demonstrated frequent changes in the co-movement of the GCC ${ }^{9)}$ stock markets, especially after the beginning US financial crisis. They found increased dependency between the GCC stock markets in times of financial crisis. Tiwari et al. (2016) analyzed the correlation and contagion between European stock markets using wavelets and showed that the level of correlation was high in the short term only during the financial crisis but the co-movement was strong in the long run throughout the analysis period. They also found that the PIIGS 10) stock markets were more correlated with Germany than the UK stock markets. Albulescu et al. (2017) studied the co-movement between six futures markets of the world stock index using a time-frequency approach and discovered that the co-movement between international markets was mainly present in the long run. However, in the very short term, contagion was present for the European stock markets in particular. Wang et al. (2017) studied the relationship between US stock markets using a method-driven multiscale correlation network combining wavelet analysis, topological methods of minimum spanning tree (MST), and planar maximally filtered

\footnotetext{
8) Europe, Pacific and North America

9) Gulf Cooperation Council

10) Portugal, Italy, Ireland, Iceland, Greece, and Spain
} 
graph (PMFG). They built MST and PMFG networks from the US stock market at different timescales. The results showed first that the topological structures and the properties of the networks varied according to timescales. Then, at small scales, there was a sectoral clustering effect in the networks. Finally, all the connections in the networks did not survive to a change of scale.

\section{Methodology}

This section presents the econometric methodology used to study the relationship between stock markets. First, an overview of maximum overlap discrete wavelet transform is provided. Then, the wavelet multiple correlation and the multiple correlation wavelet proposed by Fernandez-Macho (2012) is presented. Finally, the Diebold-Yilmaz spillovers index method proposed by Diebold and Yilmaz (2012) is described.

\section{A. Maximum Overlap Discrete Wavelet Transform (MODWT)}

The MODWT is used to implement the stock market returns at different timescales (Percival and Walden 2000). The MODWT localizes variations in the signal or time series in time and frequency simultaneously. The variability and evolution can be captured by breaking down the time series at many timescales. The MODWT, unlike other variants of wavelet methods, has important properties. First, the MODWT is well defined for all samples of size N. This method also allows a compromise between the discrete wavelet transform (DWT), which mitigates redundancy (not very realistic) and the more realistic continuous wavelet transform (CWT) that provides a highly redundant representation of the signal. In addition, unlike the CWT, the MODWT allows to have the data at each scale for easier data analysis (Percival 2008). Let $X_{t}$, the stock markets returns. The time series can be broken down by a sequence of projections into the wavelet basis:

$$
\begin{aligned}
s_{j, k} & =\int X_{t} \phi_{j, k}(t) d t \\
d_{j, k} & =\int X_{t} \psi_{j, k}(t) d t
\end{aligned}
$$

where $j=1,2, \ldots, J$, the level of multiresolution and $J=\log 2(T) ; \phi$ the father wavelet and $\psi$ the mother wavelet. $s_{j, k}$, the smooth wavelet coefficient (long-run movements) provides a smooth or overall pattern of the original signal and $d_{j, k}$ the wavelet detail coefficient (short-run 
movements) capture local fluctuations in each scale over the entire period of a time series. $\phi_{j, k}$ and $\psi_{j, k}$ are scaling and translation $\phi$ and $\psi$ obtained from and are defined as follows:

$$
\begin{aligned}
& \Phi_{j, k}(t)=2^{-j / 2} \Phi\left(2^{-j} t-k\right)=2^{-j / 2} \Phi\left(\frac{t-2^{j} k}{2^{j}}\right) \\
& \Psi_{j, k}(t)=2^{-j / 2} \Psi\left(2^{-j} t-k\right)=2^{-j / 2} \Psi\left(\frac{t-2^{j} k}{2^{j}}\right)
\end{aligned}
$$

For the break down, we use Daubechies least asymmetric (LA) wavelet filter of length 8 because the orthogonal wavelet is more suitable for the MODWT analysis.

The analysis of the series by the MODWT is usually made by the pyramidal algorithm (Mallat 1999). The multiresolution analysis of the $X_{t}$ using the MODWT can be written as follows:

$$
X_{t}=\sum_{j=1}^{J} d_{j, k}+s_{j, k}
$$

\section{B. Wavelet Multiple Comelation (WMC) and Wavelet Multiple Cross-Comelation (WMCC)}

Let $X_{t}$, a multivariate stochastic process with $X_{t}=\left(x_{1 t}, x_{2 t}, \ldots, x_{n t}\right)$ and $W_{j t}=\left(w_{1 j t}, w_{2 j t}, \ldots, w_{n j t}\right)$ their respective wavelet coefficients calculated by DWT ${ }^{11}$ ) or MODWT ${ }^{12}$ ) (Percival and Walden 2000) at each scale $\lambda_{j}$ for every $x_{i t}$ process. The WMC $\varphi_{X}\left(\lambda_{j}\right)$ can be described as one single set of multiscale correlations and can be calculated from $X_{t}$ as follows. The square root of the regression coefficient of determination corresponding at each scale $\lambda_{j}$ is calculated in the linear combination of variables $\left\{w_{i j t}, i=1, \ldots, n\right\}$, whose coefficient of determination is maximum. The coefficient of determination corresponding to the regression of a variable $z_{i}$ on

a set of regressors $\left(z_{k}, k \neq i\right)$ can be obtained by $R^{2}=\frac{1-1}{p^{i i}}$, where $p^{i i}$ is the ith diagonal element of the inverse of the correlation matrix $P$.

The wavelet multiple correlation (WMC) $\varphi_{X}\left(\lambda_{j}\right)$ is calculated as follows:

11) Discrete Wavelet Transform

12) Maximal Overlap Discrete Wavelet Transform 


$$
\varphi_{X}\left(\lambda_{j}\right)=\sqrt{1-\frac{1}{\operatorname{maxdiag} \mathrm{P}_{j}^{-1}}}
$$

where $P^{i}$ corresponds to the $n \times n$ correlation matrix of $W_{j t}$ and the maxdiag $(\cdot)$ operator allows selection of the largest element in the diagonal of the argument. In the regression of $z_{i}$ on the rest of variables in the system, the $R_{i}^{2}$ coefficient can be equal to the square of correlation between the observed values of $z_{i}$ and the fitted values $\hat{z}_{i}$ obtained from this regression. The (WMC) $\varphi_{X}\left(\lambda_{j}\right)$ is also described as follows:

$$
\varphi_{X}\left(\lambda_{j}\right)=\operatorname{corr}\left(w_{i j t}, \hat{w}_{i j t}\right)=\frac{\operatorname{Cov}\left(w_{i j t}, \hat{w}_{i j t}\right)}{\sqrt{\operatorname{Var}\left(w_{i j t}\right) \operatorname{Var}\left(\hat{w}_{i j t}\right)}}
$$

where the wavelet variances and covariance are given by:

$$
\begin{aligned}
& \operatorname{Cov}\left(w_{i j t}, \widehat{w_{i j t}}\right)=\overline{\gamma_{j}}=\frac{1}{T_{j}} \sum_{t=L_{j}^{-1}}^{T-1} w_{i j t} \widehat{w_{i j t}}, \\
& \operatorname{Var}\left(w_{i j t}\right)=\overline{\delta_{j}^{2}}=\frac{1}{T_{j}} \sum_{t=: j-1}^{T-1} w_{i j t}^{2} \\
& \operatorname{Var}\left(\widehat{w_{i j t}}\right)=\overline{\xi_{j}^{2}}=\frac{1}{T_{j}} \sum_{t=: j-1}^{T-1} \widehat{w_{i j t}^{2}}
\end{aligned}
$$

Here $w_{i j}$ on the set of regressors $\left\{w_{k j}, k \neq j\right\}$ leads to maximize the coefficient of determination $\varphi_{X}\left(\lambda_{j}\right), \hat{w}_{i j}$ is the fitted values of regression. The number of wavelet coefficients affected by the boundary associated with a wavelet filter of length $L$ and scale $\lambda_{j}$ is determined by $L_{j}=\left(2^{j}-1\right)\left(l_{j}=\left(2^{j}-1\right)(\mathrm{L}-1)+1\right.$, then $\tilde{T}=T-L_{j}+1$ is the number of coefficients unaffected by the boundary conditions.

Finally, allowing a $\operatorname{lag} \tau$ between the observed and fitted values of the variable selected as the criterion variable at each scale $\lambda_{j}$, we may also define the WMCC.

$$
\varphi_{X}\left(\lambda_{j}\right)=\operatorname{corr}\left(w_{i j t}, \hat{w}_{i j t+\tau}\right)=\frac{\operatorname{Cov}\left(w_{i j t}, \hat{w}_{i j t+\tau}\right)}{\sqrt{\operatorname{Var}\left(w_{i j t}\right) \operatorname{Var}\left(\hat{w}_{i j t+\tau}\right)}}
$$


The construction of confidence intervals assumes that $X_{t}=\left(X_{1}, \ldots ., X_{T}\right)$ is a realization of multivariate Gaussian stochastic process of (6) and $\tilde{W}_{j}=\tilde{W}_{j, 0} \ldots . \tilde{W}_{j, T-1}=\left\{\left(\tilde{w}_{1 j 0}, \ldots, \tilde{w}_{n j 0}\right),\left(\tilde{w}_{1 j, T / 2^{\prime}-1}\right)\right\}$, $\tilde{W}_{j}=\tilde{W}_{j, 0} \ldots \tilde{W}_{j, T-1}=\left\{\left(\tilde{w}_{1 j 0}, \ldots, \tilde{w}_{n j 0}\right),\left(\tilde{w}_{1 j, T / 2^{j}-1}\right)\right\}, j=1, \ldots ., J$, vectors of wavelet coefficients obtained by the MODWT at $J$ order to each univariate time series $\left(x_{i 1}, \ldots, x_{i T}\right)$ for $i=1, \ldots, n$.

If $\hat{\varphi}_{X, \tau}\left(\lambda_{j}\right)$ is the sample wavelet correlation obtained from (1), then $\tilde{Z}_{j}{ }^{a} F N\left(z_{j},\left(\frac{T}{2^{j}}-3\right)^{-1}\right)$.

Here $\tilde{Z}_{j}=\operatorname{arctanh}\left(\hat{\varphi}_{X, \tau}\left(\lambda_{j}\right)\right)$ and $F N$ refer to the folded normal distribution. The confidence interval for the sample wavelet correlation coefficient is given as follows:

$$
C I_{1-\alpha}\left(\varphi_{X, \tau}\left(\lambda_{j}\right)\right)=\tanh \left[\tilde{z}_{j} \pm \phi_{1-\alpha / 2}^{-1} / \sqrt{T / 2^{j}-3}\right]
$$

\section{Diebold-Yilmaz spillover index method}

The method proposed by Diebold and Yilmaz (2012) is applied to the wavelets coefficients obtained at different timescales. This index not only helps in measuring the spillovers but also indicates the direction of the spillovers. In addition, it measures the spillovers of one market to another and the net contribution of a market on any set of markets. The method aids in analyzing the spillovers between African stock markets over several timescales. The Diebold and Yilmaz (2012) spillover index method is an update of a previous method proposed by Diebold and Yilmaz (2009). Here, the directional spillovers are measured in a generalized VAR framework that eliminates the possible dependence of the results to the order of variables. Assume a covariance stationary of $N$-variable $\operatorname{VAR}(p)$.

$$
X_{t}=\sum_{i=1}^{p} X_{t-1}+\varepsilon_{t}
$$

where $\varepsilon:(0, \Sigma)$ and $\varepsilon$ is an i.i.d. disturbances vector.

The moving-average representation can be written as follows: $X_{t}=\sum_{i=0}^{\infty} A_{i} \varepsilon_{t-1}$ where $A_{i}$ is an $N \times N$ coefficients matrix defines as follows: $A_{i}=\phi_{1} A_{t-1}+\phi_{2} A_{t-2}+\ldots+\phi_{p} A_{t-p}$ with $A_{i}$ an identity matrix and $A_{i}=0$ for $i \leq 0$.

The moving-average coefficient allows a better understanding of the method. It is based on the decomposition of the variance for analyzing forecast error variance of each variable over 
the entire study period. The variance decomposition gives access to the fraction of the $H$-step ahead error variance in forecasting $X_{i}$ that is because of the shocks to $X_{j}, i \neq j$ for each $i$.

In general, VAR innovations are simultaneously correlated, whereas the calculation of the variance decompositions requires orthogonal innovations. The Diebold and Yilmaz (2009) method based on the Cholesky factorization depends on the order of variables. The new method uses the generalized VAR framework of Koop (1996) and Pesaran and Shin (1998), which are invariant to the order of the variables. The $H$-step ahead forecast error variance decomposition for $H=1,2, \ldots$, that uses the generalized impulse responses is defined as follows:

$$
\Theta_{i j}^{\mathfrak{g}}(\mathrm{H})=\frac{\sigma_{j j}^{-1} \sum_{h=0}^{H}\left(e_{i}^{\prime} A_{h} \Sigma e_{j}\right)^{2}}{\sum_{h=0}^{H} e_{i}^{\prime} A_{h} \Sigma A_{h}^{\prime} \Sigma e_{j}}
$$

where $i=j$, for own variance shares, $i \neq j$ for cross-variance shares or spillovers with $X_{i}$ and $X_{j}, i, j=1,2, \ldots N . \Sigma$ is the variance matrix for the error vector $\varepsilon, \sigma_{j j}$ the standard deviation of the error run for the $j t h$ equation, and $e_{i}$ the selection vector with 1 as the ith element and 0 s elsewhere.

To normalize the sum of the elements in each row equal to 1 to acquire the information in the variance decomposition matrix in the spillover index calculation, own variance and cross-variance shares or spillovers are defined as follows:

$$
\tilde{\Theta}_{i j}^{g}(\mathrm{H})=\frac{\Theta_{i j}^{\mathfrak{g}}(H)}{\sum_{j=1}^{N} \Theta_{i j}^{\mathfrak{g}}(H)}
$$

We can calculate the spillovers index using the variances obtained.

$$
S^{\mathfrak{g}}(\mathrm{H})=\frac{\sum_{i=1}^{N} \sum_{j=1, i \neq j}^{N} \tilde{\Theta}_{i j}^{q}(H)}{\sum_{i=1}^{N} \sum_{i=1}^{N} \tilde{\Theta}_{i j}^{q}(H)} \times 100=\frac{\sum_{i=1}^{N} \sum_{j=1, i \neq j}^{N} \tilde{\Theta}_{i j}^{q}(H)}{N} \times 100
$$

The problem of variance decompositions invariant to the variables order being established, the standardized elements of the generalized decomposition variance matrix are used to calculate the directional spillovers from one market $(i)$ to all other markets $(j)$ as 


$$
S_{. i}^{g}(\mathrm{H})=\frac{\sum_{j=1, j \neq i}^{N} \tilde{\Theta}_{i j}^{q}(H)}{N} \times 100
$$

The net spillover from market $(i)$ to all other markets $(j)$ is obtained as

$$
S_{i}^{\mathfrak{g}}=S_{. i}^{\mathfrak{g}}-S_{i}^{\mathfrak{g}}
$$

The net pairwise spillovers can also be calculated as follows:

$$
S_{i j}^{\mathfrak{g}}(\mathrm{H})=\left(\frac{\tilde{\Theta}_{i j}^{\mathfrak{g}}(H)}{\sum_{i, k=1}^{N} \tilde{\Theta}_{i k}^{\mathfrak{g}}(H)}-\frac{\tilde{\Theta}_{j i}^{\mathfrak{g}}(H)}{\sum_{\mathrm{j}, k=1}^{N} \tilde{\Theta}_{j k}^{\mathfrak{g}}(H)}\right) \times 100=\left(\frac{\tilde{\Theta}_{j i}^{\mathfrak{g}}(H)-\tilde{\Theta}_{i j}^{\mathfrak{g}}(H)}{N}\right) \times 100
$$

\section{Data and Empirical Results}

The study data are composed of the main indices of the six largest African stock markets in terms of capitalization, South Africa (TOP40), Egypt (EGX30), Morocco (MADEX), Nigeria (NGSE), Kenya (NSE20), and West Africa Economic and Monetary Union (BRVM10). Table 1 defines the variables. Here daily data are used. The data sample covers from January 6, 2003 to April 4, 2018 (2934 observations). Missing data are observed due to the lack of data availability at certain times and the difference in working days between the different stock exchanges. To solve this problem and from the perspective of market integration analysis, the data have been retained only on the dates common to all financial markets. The data were obtained from the Bloomberg database. The stock markets returns were calculated as follows:

$$
r_{t}=\ln \left(P_{t} / P_{t-1}\right)
$$

where $r$ are the returns and $P$ the closing index.

Table 2 presents several summary statistics of returns. All stock returns have a positive mean, and the largest standard deviation of EGX30 (Egypt) implies that it is the most volatile stock market of the panel. With the lowest standard deviation, the MADEX (Morocco) is the least volatile stock market. The skewness analysis shows a negative value ${ }^{13}$ ) for half of all stock returns. These results indicate that the left side from the (positive) mean is larger than the right

13) The thickest portion of their distributions is to the left 
Table 1. Definition of variables

\begin{tabular}{ll}
\hline Variable & \multicolumn{1}{c}{ Definition } \\
\hline TOP40 & The 40 largest companies listed on the Johannesburg Stock Exchange. \\
EGX30 & The 30 largest companies in terms of liquidity and activity listed on the Egyptian Exchange (EGX). \\
MADEX & The Moroccan Most Active Shares Index includes the most active shares listed on the Casablanca Stock \\
& Exchange. \\
NGSE & The Nigerian Stock Exchange All Shares index includes the largest companies listed on the Nigerian \\
& Stock Exchange (NGSE) in terms of capitalization. \\
NSE20 & The 20 largest companies in terms of capitalization listed on the Nairobi Stock Exchange. \\
BRVM10 & The 10 largest companies listed on the Bourse Régionale des Valeurs mobilires (BRVM) of WAEMU \\
\hline
\end{tabular}

Table 2. Descriptive Statistics of stock markets returns (all variables defined in Table 1)

\begin{tabular}{lcccccc}
\hline & TOP40 & EGX30 & MADEX & NGSE & NSE20 & BRVM10 \\
\hline Mean & 0.0002 & 0.0005 & 0.0002 & 0.0001 & $1.438^{\mathrm{e}}-04$ & 0.0001 \\
Median & 0.0004 & 0.0008 & 0.0001 & 0.0000 & $5.098^{\mathrm{e}}-05$ & 0.0000 \\
Maximum & 0.0502 & 0.1174 & 0.0255 & 0.0510 & $5.328^{\mathrm{e}}-02$ & 0.0679 \\
Minimum & -0.0481 & -0.0873 & -0.0385 & -0.0475 & -0.0667 & -0.0479 \\
Standard Deviation & 0.0064 & 0.0091 & 0.0042 & 0.0059 & 0.0051 & 0.0051 \\
Skewness & -0.1249 & -0.1503 & -0.1202 & 0.2336 & 0.3894 & 1.1914 \\
Kurtosis & 8.7845 & 21.2492 & 11.4926 & 13.9678 & 33.0046 & 24.9410 \\
Jarque-Bera & 4096.9 & 40711 & 8821.3 & 14728 & 110100 & 59526 \\
& $\left(2.2^{\mathrm{e}}-16\right)$ & $\left(2.2^{\mathrm{e}}-16\right)$ & $\left(2.2^{\mathrm{e}}-16\right)$ & $\left(2.2^{\mathrm{e}}-16\right)$ & $\left(2.2^{\mathrm{e}}-16\right)$ & $\left(2.2^{\mathrm{e}}-16\right)$ \\
\hline
\end{tabular}

side. The high coefficient of kurtosis reveals that the distribution of returns is leptokurtics. The Jarque-Bera normality test confirms the skewness and kurtosis results with a pvalue $<0.05$ for all the returns.

The wavelet coefficients are computed using the MODWT.14) For the decomposition, the Daubechies LA wavelet filter of length 8 is employed (Percival and Walden 2000). The maximum scales number of decomposition allowed is $\log 2(N) 15)$, where $N$ is the number of observations. However, for the clarity of analysis and given that the study considers high-frequency data (daily data), a decision is made to stop to seven decompositions ${ }^{16)}$ or scales (Table 3) with seven wavelet details $^{17)}$ and one smooth wavelet coefficient ${ }^{18)}$ (long-run dynamic). In fact, it is assumed that on the scale of 128 to 256 days (more than half a year), there was enough time for financial information to disseminate from one financial market to the other. Thereafter, the WMC and

\footnotetext{
14) Maximum Overlap Discrete Wavelet Transform.

15) $\log 2(2579)=11.3$

16) $J=7$

17) $D_{1}, \ldots, D_{7}$

18) $S 7$
} 
Table 3. Wavelet Scale

\begin{tabular}{ccc}
\hline Wavelets scales & Time interpretation & Time period \\
\hline$D_{i 1}$ & $2-4$ days & Intra-week \\
$D_{i 2}$ & $4-8$ days & week \\
$D_{i 3}$ & $8-16$ days & Fortnightly \\
$D_{i 4}$ & $16-32$ days & Monthly \\
$D_{i 5}$ & $32-64$ days & Monthly to Quarterly \\
$D_{i 6}$ & $64-128$ days & Quarterly to bi-annual \\
$D_{i 7}$ & $128-256$ days & Bi-annual \\
\hline
\end{tabular}

the MMCC are applied to data.

Figure 1 shows the results of the WMC. It is shown the correlations are very weak at small scales and tend to grow at large scales. At the bi-annual scale (scale 7), the returns obtained in any stock markets cannot be totally determined by the overall performance in other markets, but are quite close. It can be assumed that at very large scales, African financial markets are integrated. There are high discrepancies between the African stock markets but they tend to dissipate in horizons close to 1 year. A temporary decrease is observed in the dynamic of correlation growth at 1 month to one-quarter scales. Figure 2 shows the WMCCs for the different timescales with leads and lags (30 trading days). The name of the country whose stock market maximizes the multiple correlations against a linear combination of the rest of variables is to the right. This stock exchange can be a potential leader or follower for the other stock markets. In the present study, across all scales, the EGX30 (Egypt) is a potential leader or a follower except at scale 1, where it is the TOP40 (South Africa). The results from the WMC are confirmed by the WMCC. For scales 5 and 6 , an asymmetry (negative asymmetry) is observed due to the nonsignificance of some lags, which means that on these scales, the EGX30 delays the other indices. With regard to the other scales, there are also asymmetries, but it is difficult to say whether they are negative or positive. Based on the definition of integration in the introduction, the timescale of about half a year required for African financial markets to reach a certain level of integration shows that these markets are poorly integrated. When the results are compared to other studies of stock markets integration using the same methods in Europe and Asia (Tiwari et al. 2013, Fernandez-Macho 2012), African stock markets are not yet integrated. Indeed, the level of integration of these markets at scale 1 (Intra-Week) is already higher than that of the African financial markets at the bi-annual scale.

Further, the Diebold and Yilmaz (2012) method is applied to the data at different timescales. Table 4 shows that the stationarity hypothesis is not rejected for the scales $D_{1}$ to $D_{7}$, but it is for the $S 7$ scale. ${ }^{19)}$ Therefore, the scale $S 7$ cannot be used in view of the stationarity hypothesis

19) Case where the three tests contradict, the decision rule is a simple majority rule 
Figure 1. Wavelet Multiple Correlation of six major African stock markets returns (all variables defined in Table 1).

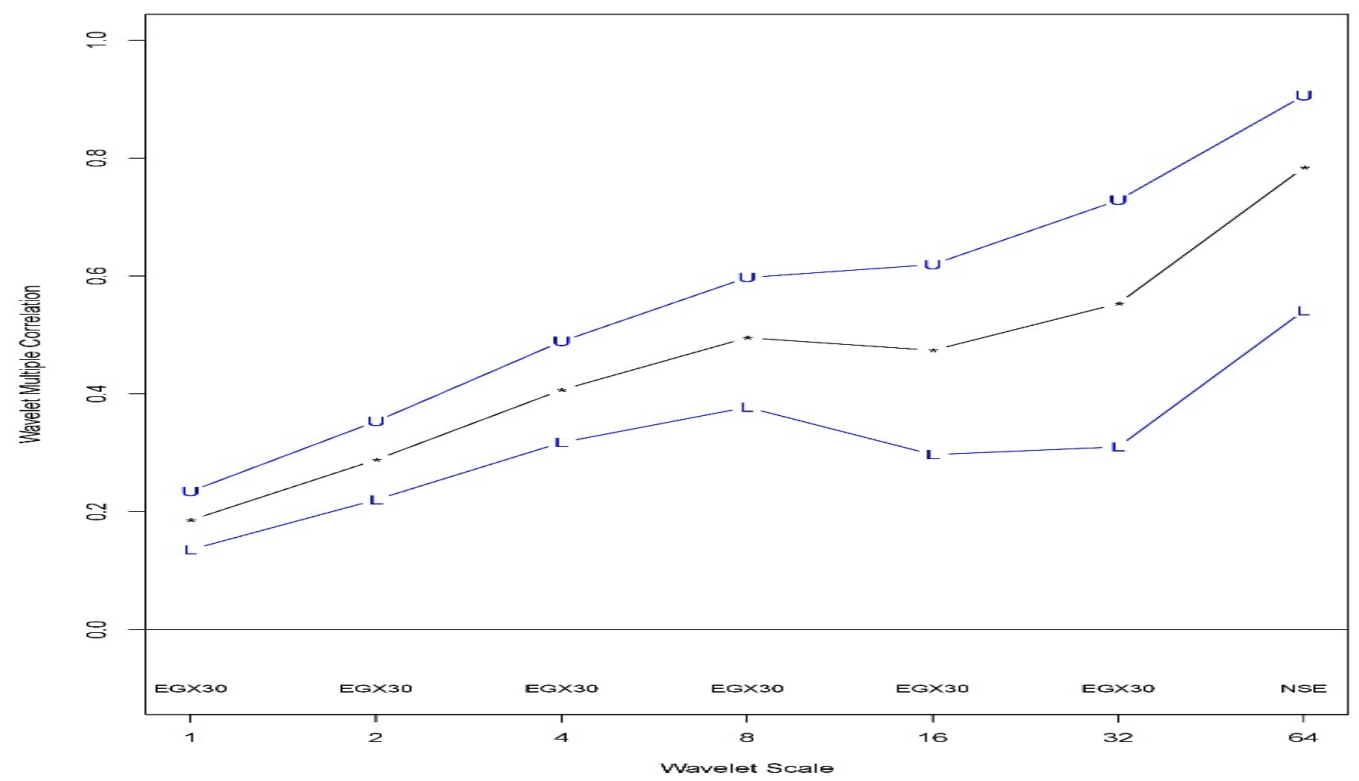

(Note) The (U) and Lower (L) lines respectively corresponds to the Upper and Lower bounds of the 95\% confidence interval.

Figure 2. Wavelet Multiple Cross-Correlation of six major African stock markets returns at different scales (all variables)

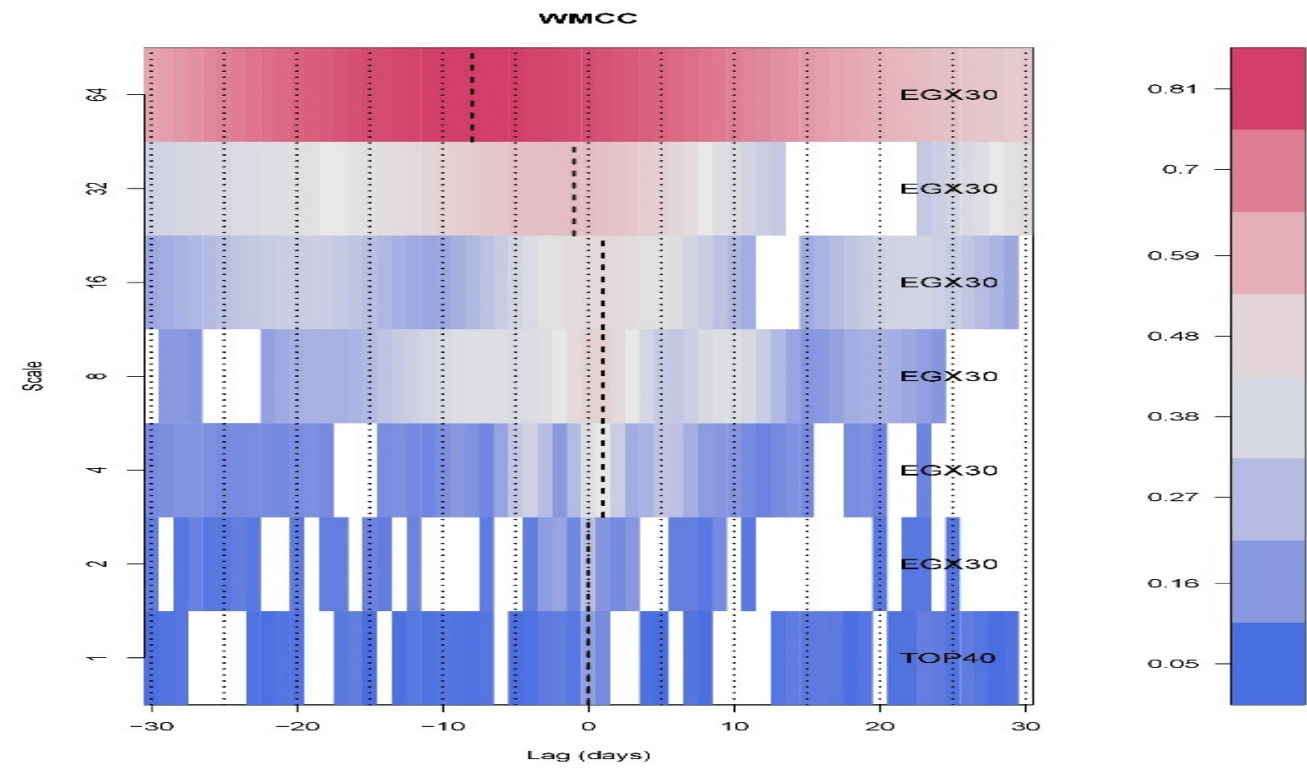

(Note) The wavelet coefficients are in the $95 \%$ confidence interval for each wavelet correlation. Areas in which the $95 \%$ interval extends to zero are indicated in white. Vertical long dotted lines indicate where the strongest wavelet correlation values are located. 
Table 4. Stationarity test results from scale 1 to scale 7 (all variables defined in Table 1).

\begin{tabular}{|c|c|c|c|}
\hline Variables & ADF ( $p$-value) & KPSS ( $p$-value) & PP ( $p$-value) \\
\hline \multicolumn{4}{|l|}{ Scale $1(D 1)$} \\
\hline TOP40 & 0.01 & 0.1 & 0.01 \\
\hline EGX30 & 0.01 & 0.1 & 0.01 \\
\hline MADEX & 0.01 & 0.1 & 0.01 \\
\hline NGSE & 0.01 & 0.1 & 0.01 \\
\hline NSE20 & 0.01 & 0.1 & 0.01 \\
\hline BRVM10 & 0.01 & 0.1 & 0.01 \\
\hline \multicolumn{4}{|l|}{ Scale $2(D 2)$} \\
\hline TOP40 & 0.01 & 0.1 & 0.01 \\
\hline EGX30 & 0.01 & 0.1 & 0.01 \\
\hline MADEX & 0.01 & 0.1 & 0.01 \\
\hline NGSE & 0.01 & 0.1 & 0.01 \\
\hline NSE20 & 0.01 & 0.1 & 0.01 \\
\hline BRVM10 & 0.01 & 0.1 & 0.01 \\
\hline \multicolumn{4}{|l|}{ Scale $3(D 3)$} \\
\hline TOP40 & 0.01 & 0.1 & 0.01 \\
\hline EGX30 & 0.1 & 0.1 & 0.01 \\
\hline MADEX & 0.01 & 0.1 & 0.01 \\
\hline NGSE & 0.01 & 0.1 & 0.01 \\
\hline NSE20 & 0.01 & 0.1 & 0.01 \\
\hline BRVM10 & 0.01 & 0.1 & 0.01 \\
\hline \multicolumn{4}{|l|}{ Scale $4(D 4)$} \\
\hline TOP40 & 0.01 & 0.1 & 0.01 \\
\hline EGX30 & 0.01 & 0.1 & 0.01 \\
\hline MADEX & 0.01 & 0.1 & 0.01 \\
\hline NGSE & 0.01 & 0.1 & 0.01 \\
\hline NSE20 & 0.01 & 0.1 & 0.01 \\
\hline BRVM10 & 0.01 & 0.1 & 0.01 \\
\hline \multicolumn{4}{|l|}{ Scale 5 (D5) } \\
\hline TOP40 & 0.01 & 0.1 & 0.01 \\
\hline EGX30 & 0.01 & 0.1 & 0.01 \\
\hline MADEX & 0.01 & 0.1 & 0.01 \\
\hline NGSE & 0.01 & 0.1 & 0.01 \\
\hline NSE20 & 0.01 & 0.1 & 0.01 \\
\hline BRVM10 & 0.01 & 0.1 & 0.01 \\
\hline \multicolumn{4}{|l|}{ Scale $6(D 6)$} \\
\hline TOP40 & 0.01 & 0.1 & 0.01 \\
\hline EGX30 & 0.01 & 0.1 & 0.01 \\
\hline MADEX & 0.01 & 0.1 & 0.01 \\
\hline NGSE & 0.01 & 0.1 & 0.01 \\
\hline
\end{tabular}


Table 4. Continued

\begin{tabular}{lccc}
\hline Variables & ADF $(p$-value $)$ & KPSS $(p$-value $)$ & PP $(p$-value $)$ \\
\hline NSE20 & 0.01 & 0.1 & 0.01 \\
BRVM10 & 0.01 & 0.1 & 0.01 \\
Scale 7 (D) & & & 0.08296 \\
TOP40 & 0.01507 & 0.1 & 0.08267 \\
EGX30 & 0.01 & 0.1 & 0.09602 \\
MADEX & 0.01 & 0.1 & 0.09326 \\
NGSE & 0.01 & 0.1 & 0.15270 \\
NSE20 & 0.01 & 0.1 & 0.09144 \\
BRVM10 & 0.01 & 0.1 & 0.6596 \\
Scale 7 $(S 7)$ & & & 0.99 \\
TOP40 & 0.5383 & 0.01 & 0.99 \\
EGX30 & 0.7977 & 0.01 & 0.9689 \\
MADEX & 0.6952 & 0.01 & 0.99 \\
NGSE & 0.1333 & 0.01 & 0.9032 \\
NSE20 & 0.2261 & 0.01 & 0.01 \\
BRVM10 & 0.01 & & \\
\hline
\end{tabular}

of the VAR models. This agrees with the wavelet theory because the $S 7$ scale captures the long-run trend and nonstationary components of the series (Schleicher 2002). To determine the optimum VAR lag, the AIC, BIC, and HQ are used on the original returns data (Table 5). One lag is chosen based on the different criteria. Table 6 clearly shows that integration varies according to the timescales. The spillovers between African stock markets are weak and tend to increase as the scales increase.

The spillovers are down to scale 5 . The results confirm those obtained by the WMC. The WMCC showed that at scale 1, the South Africa stock market is a potential leader or a follower of other African financial markets. In fact, it receives the most spillovers from other markets on this scale. The scale 1 (intra-week) of the spillovers table shows that the Egyptian market shares most of the spillovers. However, it should be noted that the majority of the Egyptian spillovers are mainly directed toward South African stock market in the short run and Kenyan stock market in the long run.

The spillovers from South Africa to other markets are higher than those from Egypt. The South African financial market thus influences the overall African financial market more than the Egyptian financial market. In terms of other scales, the Egyptian financial market is the most open. ${ }^{20)}$ The WAEMU has the least open and least influential financial market of the sample. At scales 1 and 2 (intra-week to week), African financial markets are segmented. Therefore,

20) The stock market that receives the most of the spillovers 
Table 5. Lag order selection of the VAR model

\begin{tabular}{cccccc}
\hline Lag Order & 1 & 2 & 3 & 4 & 5 \\
\hline AIC & $-6.2067 \mathrm{e}+01$ & $-6.2066 \mathrm{e}+01$ & $-6.2072 \mathrm{e}+01^{*}$ & $-6.2071 \mathrm{e}+01$ & $-6.2071 \mathrm{e}+01$ \\
BIC & $-6.1981 \mathrm{e}+01^{*}$ & $-6.1907 \mathrm{e}+01$ & $-6.1839 \mathrm{e}+01$ & $-6.1764 \mathrm{e}+01$ & $-6.1691 \mathrm{e}+01$ \\
HQ & $-6.2036 \mathrm{e}+01^{*}$ & $-6.2009 \mathrm{e}+01$ & $-6.1988 \mathrm{e}+01$ & $-6.1960 \mathrm{e}+01$ & $-6.1934 \mathrm{e}+01$ \\
\hline
\end{tabular}

Table 6. Spillovers table of stock markets returns at different scales: from January 2, 2003 to April 4, 2018 (all variables defined Table 1).

\begin{tabular}{|c|c|c|c|c|c|c|c|}
\hline Scale 1 & Egypt & Kenya & Morocco & Nigeria & South Africa & WAEMU & From others \\
\hline Egypt & 96.49 & 0.27 & 0.56 & 0.10 & 2.52 & 0.07 & 3.5 \\
\hline Kenya & 0.04 & 98.93 & 0.16 & 0.13 & 0.43 & 0.31 & 1.1 \\
\hline Morocco & 0.37 & 0.29 & 97.35 & 0.88 & 0.96 & 0.15 & 2.6 \\
\hline Nigeria & 0.10 & 0.34 & 0.34 & 99.05 & 0.07 & 0.10 & 0.9 \\
\hline South Africa & 4.06 & 0.86 & 0.24 & 0.22 & 94.54 & 0.08 & 5.5 \\
\hline WAEMU & 0.14 & 0.98 & 0.68 & 0.21 & 0.16 & 97.85 & 2.2 \\
\hline To others & 4.7 & 2.7 & 2.0 & 1.5 & 4.1 & 0.7 & 15.8 \\
\hline Scale 2 & Egypt & Kenya & Morocco & Nigeria & South Africa & WAEMU & From others \\
\hline Egypt & 91.21 & 2.52 & 0.71 & 0.87 & 4.43 & 0.26 & 8.8 \\
\hline Kenya & 2.23 & 93.91 & 0.33 & 1.53 & 0.29 & 1.71 & 6.1 \\
\hline Morocco & 0.90 & 0.46 & 96.78 & 0.25 & 1.36 & 0.25 & 3.2 \\
\hline Nigeria & 1.89 & 1.41 & 0.90 & 94.08 & 0.98 & 0.74 & 5.9 \\
\hline South A & 3.27 & 0.11 & 1.75 & 0.57 & 94.29 & 0.00 & 5.7 \\
\hline WAEMU & 0.17 & 0.63 & 0.59 & 0.98 & 0.16 & 97.47 & 2.5 \\
\hline To others & 8.5 & 5.1 & 4.3 & 4.2 & 7.2 & 3.0 & 32.3 \\
\hline Scale 3 & Egypt & Kenya & Morocco & Nigeria & South Africa & WAEMU & From others \\
\hline Egypt & 64.51 & 1.52 & 3.80 & 2.40 & 27.56 & 0.20 & 35.5 \\
\hline Kenya & 3.01 & 89.92 & 2.13 & 0.16 & 2.52 & 2.26 & 10.1 \\
\hline Morocco & 3.70 & 0.91 & 90.48 & 0.75 & 3.87 & 0.29 & 9.5 \\
\hline Nigeria & 4.79 & 0.20 & 2.08 & 80.39 & 5.95 & 6.59 & 19.6 \\
\hline South Africa & 9.80 & 0.45 & 2.75 & 1.18 & 85.20 & 0.62 & 14.8 \\
\hline WAEMU & 0.06 & 1.57 & 1.06 & 3.75 & 0.33 & 93.23 & 6.8 \\
\hline To others & 21.4 & 4.6 & 11.8 & 8.2 & 40.2 & 10.0 & 96.3 \\
\hline Scale 4 & Egypt & Kenya & Morocco & Nigeria & South Africa & WAEMU & From others \\
\hline Egypt & 65.98 & 3.89 & 2.17 & 0.74 & 23.67 & 3.55 & 34.0 \\
\hline Kenya & 12.28 & 62.04 & 2.41 & 1.50 & 19.76 & 2.02 & 38.0 \\
\hline Morocco & 3.54 & 1.55 & 81.17 & 1.99 & 3.78 & 7.97 & 18.8 \\
\hline Nigeria & 2.43 & 1.84 & 0.58 & 88.30 & 6.83 & 0.03 & 11.7 \\
\hline South Africa & 8.41 & 3.60 & 10.94 & 0.50 & 76.36 & 0.19 & 23.6 \\
\hline WAEMU & 0.60 & 2.84 & 1.83 & 0.05 & 0.04 & 94.65 & 5.3 \\
\hline To others & 27.3 & 13.7 & 17.9 & 4.8 & 54.1 & 13.8 & 131.5 \\
\hline
\end{tabular}


Table 6. Continued

\begin{tabular}{|c|c|c|c|c|c|c|c|}
\hline Scale 5 & Egypt & Kenya & Morocco & Nigeria & South Africa & WAEMU & From others \\
\hline Egypt & 77.44 & 1.85 & 2.06 & 4.34 & 14.09 & 0.22 & 22.6 \\
\hline Kenya & 8.54 & 78.08 & 0.15 & 3.53 & 9.56 & 0.14 & 21.9 \\
\hline Morocco & 1.60 & 0.05 & 83.97 & 2.26 & 5.20 & 6.91 & 16.0 \\
\hline Nigeria & 7.42 & 1.44 & 0.37 & 82.78 & 7.98 & 0.01 & 17.2 \\
\hline South Africa & 9.06 & 2.60 & 3.26 & 1.47 & 83.47 & 0.15 & 16.5 \\
\hline WAEMU & 0.97 & 1.37 & 2.20 & 0.02 & 0.45 & 94.99 & 5.0 \\
\hline To others & 27.6 & 7.3 & 8.0 & 11.6 & 37.3 & 7.4 & 99.3 \\
\hline Scale 6 & Egypt & Kenya & Morocco & Nigeria & South Africa & WAEMU & From others \\
\hline Egypt & 70.20 & 13.18 & 1.81 & 1.14 & 13.51 & 0.15 & 29.8 \\
\hline Kenya & 14.12 & 71.69 & 1.00 & 7.42 & 5.72 & 0.05 & 28.3 \\
\hline Morocco & 4.96 & 0.27 & 90.32 & 0.13 & 0.59 & 3.73 & 9.7 \\
\hline Nigeria & 6.99 & 4.04 & 0.03 & 86.19 & 2.19 & 0.56 & 13.8 \\
\hline South Africa & 11.46 & 5.99 & 0.06 & 0.41 & 81.47 & 0.62 & 18.5 \\
\hline WAEMU & 2.32 & 0.54 & 1.23 & 1.49 & 4.02 & 90.39 & 9.6 \\
\hline To others & 39.8 & 24.0 & 4.1 & 10.6 & 26.0 & 5.1 & 109.7 \\
\hline Scale 7 & Egypt & Kenya & Morocco & Nigeria & South Africa & WAEMU & From others \\
\hline Egypt & 59.88 & 15.66 & 14.75 & 2.51 & 6.34 & 0.86 & 40.1 \\
\hline Kenya & 19.59 & 61.45 & 7.19 & 4.63 & 6.95 & 0.20 & 38.6 \\
\hline Morocco & 23.25 & 10.59 & 61.34 & 0.44 & 2.87 & 1.51 & 38.7 \\
\hline Nigeria & 5.42 & 9.54 & 1.56 & 83.00 & 0.29 & 0.19 & 17.0 \\
\hline South Africa & 8.33 & 7.92 & 2.50 & 0.55 & 79.90 & 0.81 & 20.1 \\
\hline WAEMU & 4.81 & 0.39 & 3.23 & 0.88 & 4.20 & 86.48 & 13.5 \\
\hline To others & 61.4 & 44.1 & 29.2 & 9.0 & 20.7 & 3.6 & 168.0 \\
\hline
\end{tabular}

there are opportunities for capital diversification and risk sharing for each of them on all other markets. At scale 3, the spillovers between stock markets are increasing; however, the Moroccan and WAEMU stock markets still offer strong risk-sharing opportunities for the other financial markets. At scale 4, the relations between markets increase sharply, thus increasing the risk of the portfolio between the markets except between those of the UEMOA and Nigeria stock exchanges, which allow diversification of the capital. At scales 5, 6, and even 7, where the relations between the markets are the highest, the WAEMU market remains a concrete possibility for the other financial markets to diversify their portfolios and minimize the investment risk.

For a more focused analysis of the stock market integration, the present study examines the dynamic spillovers among African stock markets. This will aid in analyzing the evolution of spillovers during the US financial crisis, the European debt crisis, and the period of increasing measures to integrate African stock markets. Similarly to that used by Diebold and Yilmaz (2012), the length of the rolling sample used in the present study is 200 days.

Figure 3 shows that the evolution of spillovers varies according to the economic conditions. 
The US financial crisis is characterized by an upward trend in spillovers between African financial markets during the stock market crash of 2008 at almost all scales. However, at scales 2, 3, and 4 , the rise in spillovers is much more significant, which might be due to the non-automatic effect of this crisis on the African financial markets (nonsignificant effect at scale 1: intra-week). These increases imply that the global impact of the crisis may have prompted African markets that were more resilient to the negative effects of this crisis to distance rather than integrate with the global markets that have been heavily affected to optimize their investment portfolios. In contrast to the US financial crisis, the European debt crisis has had a direct impact on the spillovers between African markets. Indeed, the beginning of this crisis is marked by an increase in spillovers at scale 1 . This direct impact could be a result of the strong economic and financial relationship between Africa and Europe (Africa-Europe economic relations often stronger than Africa-Africa economic relations). European financial markets were badly affected by the crisis, compelling the African stock markets to diversify their capital on African stock markets rather than in Europe. The present study observed that the end of the crisis is characterized by a decline in spillovers between African financial markets, which may be synonymous with the resumption of European financial activities on the African stock market. Compared with periods during crises and even before the crises, in the past few years, which have witnessed a slew of measures promoting the integration of African financial markets, spillovers between African financial markets are quite weak. Only scale 3 is experiencing a sharp rise in spillovers between African markets.

These results confirm the hypothesis of contagion between financial markets during times of crisis (Forbes and Rigobon 2002, McAleer and Nam 2005). Moreover, this decline in spillovers in the past few years suggests the possibility of diversification of capital during this period and those even on the scales where the stock markets are the most correlated (scales 4 and 7).

The results obtained show that the various measures implemented to integrate the African financial market have not had the desired effect. Spillovers between financial markets in recent years are generally declining. Development and the openness of African financial markets to world markets is one of the reasons for this decline in trade between African financial markets. Indeed, African financial markets have become more globally appealing (Raleigh 2014). In addition, while fostering relations with each other, African markets have also networked with world markets more efficiently. This could be a drag on the integration of African financial markets to some extent. 
Figure 3. Total spillovers from scale 1 to scale 7 (all variables defined in Table 1). Scale 1

Scale 2
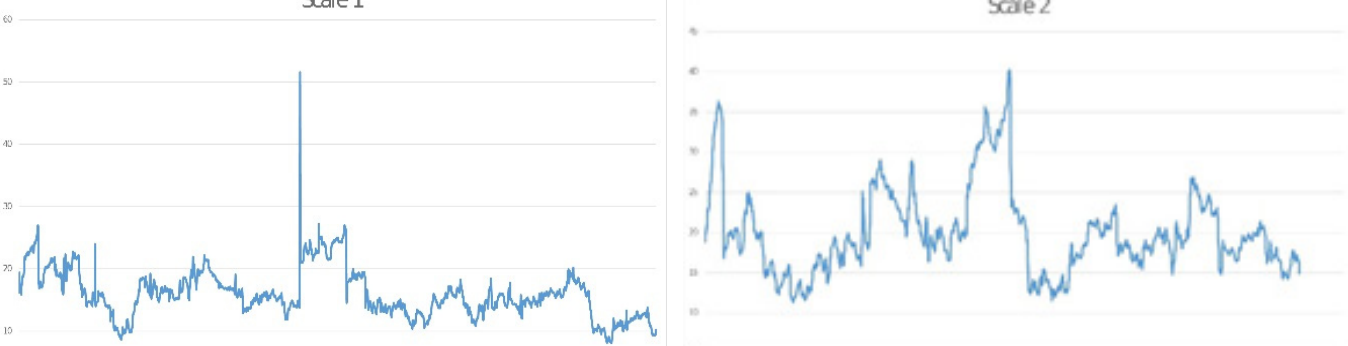

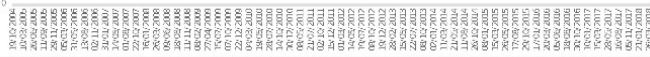

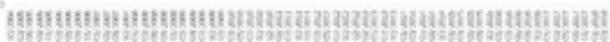

Scale 3

Scale 4

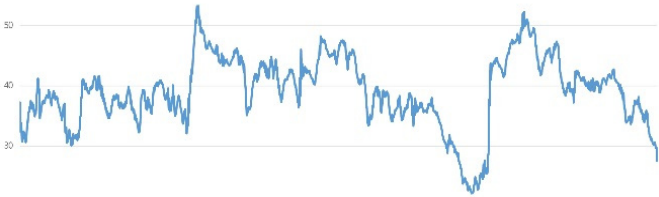

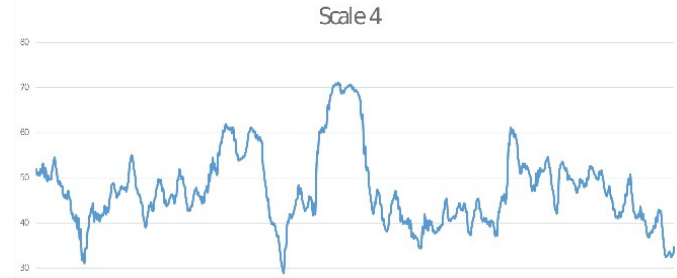

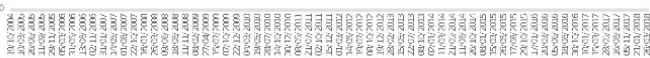

Scale 5

Scale 6

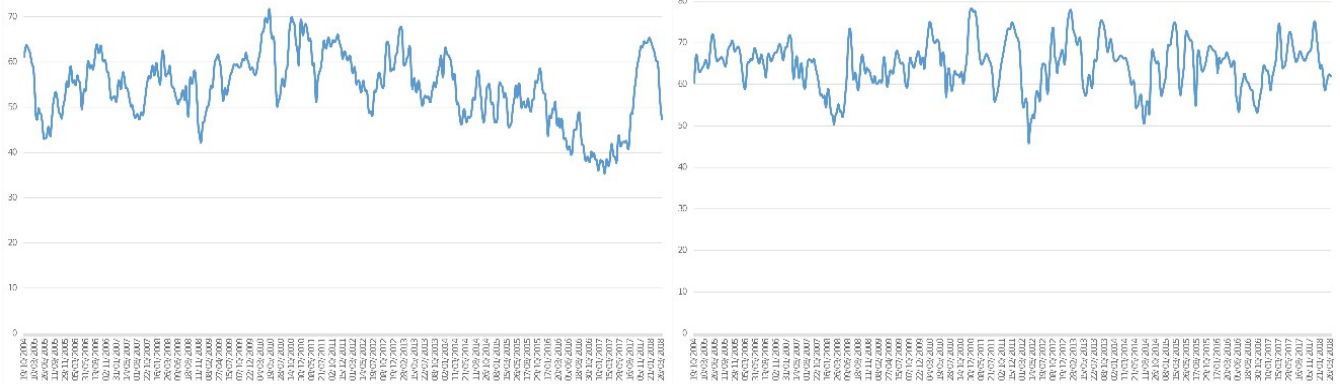
Scale 7

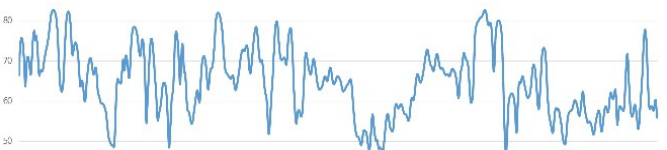

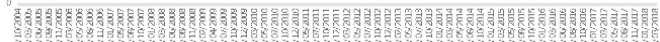

(Note) Spillovers index from six African stock markets to six African stock markets 


\section{Conclusion}

The present study examines the relationships between the six largest African stock markets (South Africa, Egypt, Morocco, Nigeria, Kenya, and WAEMU) at different timescales. It confirms whether the numerous measures and reforms implemented for better integration of these financial markets have been effective. The wavelet approach and the VAR modeling are combined to analyze the level of integration and the spillovers between the six African stock markets at seven timescales (Diebold and Yilmaz 2012, Fernandez-Macho 2012).

The study results show that African stock markets are weakly integrated. The integration is low at small timescales (intra-week to monthly) and appear to grow at large (bi-annual) timescales. Across all scales, with the exception of the intra-week scale or the South African stock market, the Egyptian stock market is the potential leader or a follower of other African markets. The crisis periods (the US financial crisis and the European debt crisis) are characterized by an increase of spillovers between African financial markets. The highest spillovers are seen during the European debt crisis, thus confirming the contagion between financial markets in times of financial crisis (Forbes and Rigobon 2002, McAleer and Nam 2005). It may also be an indirect impact of financial crises on African financial markets through these negative effects on global markets (Kasekende et al. 2009). Moreover, the spillovers between African financial markets have been observed to be declining in recent years at almost all scales, except at scales 3 .

Therefore, it can be concluded that despite all the reforms of recent years for better integration, African stock markets are far from being integrated. A decline in spillovers was observed between African stock markets in recent years. This decline in integration could be due to African stock markets becoming viable avenues of diversifying capital for world financial markets (Raleigh 2014). Financial exchanges with the outside world may have increased to the detriment of regional exchanges. Finally, this weak integration of African stock markets at a smaller scale offers huge potential benefits of international portfolio diversification in these countries (Grubel 1968).

The study findings are relevant for diversification strategies and to policy makers. From the perspective of their segmentation and development, WAEMU and Nigeria stock markets present considerable investment and risk diversification opportunities at almost all the scales. However, competent authorities should intensify their efforts in implementation the common standards promoting the stock markets integration and trade between African stock exchanges by creating the conditions for the development of popular shareholding in Africa considering the substantial economic advantages stemming from this integration (Fish and Biekpe 2002, Irving 2005). 


\section{References}

Adjasi, C.K.D., and N.B. Biekpe. (2006). "Co integration and dynamic causal links amongst African stock markets." Investment Management and Financial Innovations 4, 102-119.

Agyei-Ampomah, Sam, (2008). An Empirical Examination of the Inter-Linkages between African Stock Markets (September 1, 2008). Available at SSRN: https://ssrn.com/abstract=1311325 or http://dx.doi.or $\mathrm{g} / 10.2139 / \mathrm{ssrn} .1311325$

Albulescu, C. T., D. Goyeau, and A. K. Tiwari. (2017). "Co-movements and contagion between international stock index futures markets." Empirical Economics 52, no. 4, 1529-1568.

Aloui, C. and B. Hkiri, (2014). "Co-movements of GCC emerging stock markets: New evidence from wavelet coherence analysis." Economic Modelling 36, 421-431.

Economic Commission for Africa. (2008). Vers l'integration montaire et financière en Afrique. Assessing Regional Integration in Africa ARIA III.

African Securities Exchanges Association YearBook. (2012).

African Securities Exchanges Association. (2015). Annual Report \& Statistics.

Bagehot, W. (1873). Lombard Street. Homewood, IL: Richard D. Irwin, 1962 Edition.

Barari, M. (2004). "Equity market integration in Latin America: A time-varying integration score analysis." International Review of Financial Analysis 13, no. 5, 649-668.

Boako, G., and P. Alagidede. (2016). "African stock markets convergence: Regional and global analysis." Finance Research Letters 18, 317-321.

Boako, G., and P. Alagidede. (2017). "Co-movement of Africas equity markets: Regional and global analysis in the frequencytime domains." Physica A: Statistical Mechanics and Its Applications 468, 359-380.

Boako, G., P. Alagidede, (2018). "African stock markets in the midst of the global financial crisis: Recoupling or decoupling?." Research in International Business and Finance.

Boamah, N.A. (2013). Global Integration of African Stock Markets. Available at SSRN 2313538.

Candelon, B., A. Hecq, and W. Verschoor. (2005). "Measuring common cyclical features during financial turmoil: evidence of interdependence not contagion." Journal of International Money and Finance 24, 1317-1334.

Collins, D., and N. Biekpe. (2003a). "Contagion: a fear for African equity markets?.” Journal of Economics and Business 55, 285-297.

Collins, D., and N. Biekpe. (2003b). "Contagion and interdependence in African stock markets." South African Journal of Economics 71, 181-194.

Diebold, F. X., and K. Yilmaz. (2009). "Measuring financial asset return and volatility spillovers, with application to global equity markets." The Economic Journal 119, 158-171.

Diebold, F.X., and K. Yilmaz. (2012). "Better to give than to receive: Predictive directional measurement of volatility spillovers.” International Journal of Forecasting, 28, 57-66.

Engle, R.F., and C.W.J. Granger. (1987). "Co-integration and error correction: representation, estimation, and testing." Econometrica: journal of the Econometric Society 55, no. 2, 251-276.

Fernndez-Macho, J. (2012). "Wavelet multiple correlation and cross-correlation: A multiscale analysis 
of Eurozone stock markets." Physica A: Statistical Mechanics and its Applications 391, 1097-1104. Fish, T., and N. Biekpe. (2002). "Regional African stock markets indices." S. Afr. J. Bus. Manage 33, no. $1,11-19$.

Forbes, K.J., and R. Rigobon. (2002). "No contagion, only interdependence: measuring stock market co-movements." The Journal of Finance 57, 2223-2261.

Fowowe, B., and M. Shuaibu. (2016). "Dynamic spillovers between Nigerian, South African and international equity markets." International Economics 148, 59-80.

Gallegati, M. (2005). A wavelet analysis of MENA stock markets. Department of Economics.

Graham, M., J. Kiviaho, and J. Nikkinen. (2012). "Integration of 22 emerging stock markets: a three-dimensional analysis." Global Finance Journal 23, 34-47.

Graham, M., J. Kiviaho, J. Nikkinen, and M. Omran. (2013). "Global and regional co-movement of the MENA stock markets." Journal of Economics and Business 65, 86-100.

Graham, M., and J. Nikkinen. (2011). "Co-movement of the Finnish and international stock markets: a wavelet analysis." The European Journal of Finance 17, 409-425.

Grubel, H. G. (1968). "Internationally diversified portfolios: welfare gains and capital flows." The American Economic Review 58, no. 5, 1299-1314.

Hicks, J.R. (1969). A theory of economic history. OUP Catalogue.

Hooy, C. W., and K. P. Lim. (2013). "Is market integration associated with informational efficiency of stock markets?." Journal of Policy Modeling 35, no. 1, 29-44.

Irving, M. J. (2005). Regional Integration of Stock Exchanges in Eastern and Southern Africa: Progress and Prospects (EPub), No. 5-122. International Monetary Fund.

Kasekende, L. A., L. Ndikumana, and T. Rajhi. (2009). Impact of the global financial and economic crisis on Africa. African Development Bank.

Koop, G., M.H. Pesaran, and S.M. Potter. (1996). "Impulse response analysis in nonlinear multivariate models." Journal of Econometrics, 74, 119-147.

Levine, R. (1997). "Financial development and economic growth: views and agenda, Journal of economic literature 35, no.2, 688-726.

Lehkonen, H. (2014). "Stock market integration and the global financial crisis." Review of Finance 19, no. $5,2039-2094$.

Loh, L. (2013). "Co-movement of Asia-Pacific with European and US stock market returns: A crosstime-frequency analysis." Research in International Business and Finance 29, 1-13.

Lugangwa, E. (2012). Regional African Stock Exchanges on Agenda.

Madaleno, M., and C. Pinho. (2012). "International stock market indices comovements: a new look." International Journal of Finance \& Economics 17, 89-102.

Mallat, S. (1999). A Wavelet Tour of Signal Processing. Academic press.

McAleer, M., and J.C.W. Nam. (2005). "Testing for contagion in ASEAN exchange rates." Mathematics and Computers in Simulation 68, 517-525.

Mensah, J. O., and P. Alagidede, (2017). "How are Africa's emerging stock markets related to advanced markets? Evidence from copulas." Economic Modelling 60, 1-10.

Percival, D. B. (2008). "Analysis of geophysical time series using discrete wavelet transforms: An overview." 
In Nonlinear Time Series Analysis in the Geosciences, edited by , 61-79. Springer, Berlin, Heidelberg. Percival, D.B., and A.T. Walden. (2000). Wavelet Methods for Time Series Analysis. Cambridge University Press, Cambridge, England.

Pesaran, H.H., and Y. Shin. (1998). "Generalized impulse response analysis in linear multivariate models." Economics letters 58, 17-29.

PricewaterhouseCoopers (PwC). (2015). Africa Capital Markets Watch.

PricewaterhouseCoopers (PwC). (2016). Africa Capital Markets Watch.

Raleigh, P. (2014). "L'Afrique note: le rôle de la notation dans le développement des marches financières Africaines." Revue d'Economie Financière 116, 229-242.

Rua, A., and L.C. Nunes, (2009). "International comovement of stock market returns: A wavelet analysis." Journal of Empirical Finance 16, 632-639.

Schleicher, C. (2002). An introduction to wavelets for economists. Bank of Canada.

Schumpeter, J. (1912). The Economic Theory of Development.

Sugimoto, K., T. Matsuki, and Y. Yoshida. (2014). "The global financial crisis: An analysis of the spillover effects on African stock markets." Emerging Markets Review 21, 201-233.

Tiwari, A.K., A.B. Dar, N. Bhanja, and A. Shah. (2013). "Stock market integration in Asian countries: Evidence from wavelet multiple correlations." Journal of Economic Integration, 28, 441-456.

Tiwari, A. K., M. I. Mutascu, and C. T. Albulescu. (2016). "Continuous wavelet transform and rolling correlation of European stock markets." International Review of Economics \& Finance 42, 237-256.

UNCTAD. (2014). Economic Development in Africa Report CATALYSING INVESTMENT FOR TRANSFORMATIVE GROWTH IN AFRICA, United Nations publication, UNCTAD/ALDC/ AFRICA/2014, New York and Geneva.

Wang, Z., J. Yang, and D.A. Bessler. (2003). "Financial crisis and African stock market integration." Applied Economics Letters 10, 527-533.

Wang, G. J., C. Xie, and S. Chen. (2017). "Multiscale correlation networks analysis of the US stock market: A wavelet analysis." Journal of Economic Interaction and Coordination 12, no. 3, 561-594. 